\title{
Experimental Biology of Cerebral Hypoxia-Ischemia: Relation to Perinatal Brain Damage
}

\author{
ROBERT C. VANNUCCI \\ Division of Pediatric Neurology, The Milton S. Hershey Medical Center, The Pennsylvania State University, \\ Hershey, Pennsylvania 17033
}

\begin{abstract}
Cerebral hypoxia-ischemia remains a major cause of acute perinatal brain injury, leading ultimately to neurologic dysfunction manifest as cerebral palsy, mental retardation, and epilepsy. Research in experimental animals over the past 10 or more years has expanded greatly our understanding of the cellular and molecular events that occur during a hypoxic-ischemic insult to brain, and recent discoveries have suggested that metabolic pertubations arising in the recovery period after resuscitation contribute substantially to the nature and extent of neuronal destruction. The review focuses on those neurochemical processes responsible for the maintenance of cellular homeostasis and how these mechanisms fail in hypoxia-ischemia to culminate in brain damage. Knowledge of these critical events has opened new avenues of potential therapy for the fetus and newborn infant subjected to cerebral hypoxiaischemia to prevent the serious delayed effects of perinatal brain injury. (Pediatr Res 27: 317-326, 1990)
\end{abstract}

\section{Abbreviations}

CBF, cerebral blood flow

$\sim \mathrm{P}$, anhydride phosphate bond

CPK, creatine phosphokinase

PFK, phosphofructokinase

PCr, phosphocreatine

. $\mathrm{O}_{2}{ }^{-}$, superoxide anion

. $\mathrm{OH}^{-}$, hydroxyl radical

$\mathrm{H}_{2} \mathrm{O}_{2}$, hydrogen peroxide

NMDA, N-methyl-D-aspartate

$\mathrm{IP}_{3}$, inositol-1,4,5-trisphosphate

DAG, diacylglycerol

ER, endoplasmic reticulum

VSCC, voltage-sensitive calcium channel

AOCC, agonist-operated calcium channel

FADH, flavin adenine dinucleotide, reduced form

Perinatal cerebral hypoxia-ischemia typically is initiated by compromised placental or pulmonary gas exchange which leads to systemic hypoxia/anoxia with or without concurrent hypercapnia (asphyxia) (1). Hypoxia/hypercapnia increases CBF adequate to maintain brain metabolism stable until cerebral ischemia supervenes owing to cardiac depression with secondary bradycardia and systemic hypotension. With the neuronal oxygen and glucose debt arising from ischemia, oxidative metabo-

Received August 16, 1989; accepted November 30, 1989.

Supported by Grants HD-09109, HD-15738, HD-19913, and HL-19190 from the NIH and by grants from the American Heart Association and American Diabetes Association. lism shifts to anaerobic glycolysis with its inefficient generation of high-energy phosphate reserves necessary to maintain cellular ionic gradients and other metabolic processes. Ultimately, cellular energy failure occurs, which, if not promptly reversed, results in death of the cell.

Over the past decade, a wealth of research has expanded our knowledge of those critical cellular metabolic events that eventually lead to tissue injury arising from hypoxia-ischemia. Investigations have shown that hypoxia-ischemia sets in motion a cascade of biochemical alterations that are initiated during the course of the insult and that proceed well into the recovery period after resuscitation. This review will highlight those cellular processes involved in this metabolic cascade and how they evolve into perinatal hypoxic-ischemic brain damage.

\section{CELLULAR ENERGY TRANSFORMATIONS}

ATP is the primary energy modulator of the cell (2-4). Its two $\sim \mathrm{P}$ exist at an energy level capable of providing the necessary driving force for innumerable biochemical reactions and physiologic processes. ATP not only promotes energy consuming reactions but also drives physiologic processes (e.g. ion pumping) by acid hydrolysis. As such, the compound provides the cellular free energy necessary to maintain neuronal viability with its specialized function.

Under physiologic conditions, cellular ATP is maintained remarkably stable, as the rate of energy consumption by endergonic reactions is exactly balanced by the rate of ATP production. The cell's ability to maintain ATP constant, even under situations of increased energy expenditure, is dependent on those biochemical processes that generate ATP. The first and most important is the oxidative phosphorylation of $\mathrm{NADH}$, which takes place within mitochondria. Mitochondrial oxidation is a highly efficient process which couples molecular oxygen to the hydrogen ion of $\mathrm{NADH}$ (and FADH) to form water coincident with the phosphorylation of ADP to form ATP. A small amount of ATP also is produced by so-called substrate phosphorylation, which occurs within mitochondria as well as the cytosol $(3,5-$ 7).

In addition to substrate and oxidative phosphorylation, which are net energy producing processes, two other mechanisms exist to maintain cellular ATP constant $(3,4)$. These include the CPK and adenylate kinase equilibria, biochemical reactions that simply transfer energy $(\sim \mathrm{P})$ from one compound to another. CPK catalyzes a reversible transfer of $\sim \mathrm{P}$ between phosphocreatine $(\mathrm{PCr})$ and ATP:

$$
\mathrm{PCr}+\mathrm{ADP}+\mathrm{H}^{+} \leftrightarrows \mathrm{ATP}+\mathrm{Cr}
$$

The adenylate kinase reaction catalyzes the conversion of ADP to ATP:

$$
2 \mathrm{ADP} \leftrightarrows \mathrm{ATP}+\mathrm{AMP}
$$


Owing to their equilibrium constants, both reactions serve to maintain an optimal intracellular concentration of ATP even under situations of reduced ATP synthesis by oxidative phosphorylation.

As mentioned previously, ATP is the critical regulator of cell function owing to its role in energy transformations. One especially vital function involves the work required to preserve ionic gradients across plasma and intracellular membranes. The major ions whose movements consume ATP are $\mathrm{Na}^{+}, \mathrm{K}^{+}$, and $\mathrm{Ca}^{++}$ $(3,4)$. It has been concluded that under normal conditions ion pumping required $50-60 \%$ of total energy expenditure (or oxygen consumption) by the cell, the major fraction of which is used for $\mathrm{Na}^{+} / \mathrm{K}^{+}$exchange (4).

Tissue hypoxia denotes a cellular oxygen debt, owing typically to inadequate oxygen delivery $\left(\mathrm{CBF} \times \mathrm{SaO}_{2}\right)$ via nutrient arteries. When the tissue (mitochondrial) partial pressure of oxygen falls below a critical value $(<0.1 \mathrm{~mm} \mathrm{Hg})$, the cytochrome system of mitochondria becomes unsaturated, and reducing equivalents (NADH, FADH) begin to accumulate $(8,9)$. ATP production by oxidative phosphorylation is curtailed, with concurrent increases in cellular ADP and AMP as cytosolic ATP hydrolysis continues to drive endergonic reactions (3). The elevations in ADP and AMP serve to stimulate glycolysis, through activation of its key regulatory enzyme, PFK. Unlike oxidative phosphorylation, which produces $36 \mathrm{~mol}$ of ATP for every mol of glucose consumed, glycolysis is an inefficient method to generate ATP by substrate phosphorylation, with the net production of only $2 \mathrm{~mol}$ of ATP $/ \mathrm{mol}$ of glucose consumed. To produce the amount of ATP equivalent to that of oxidative phosphorylation, glycolysis would need to increase to a rate 18 times its basal flux. In reality, glycolysis, even when maximally stimulated by total cerebral ischemia, is capable of increasing only 4- to 5-fold, owing in part to the concurrent accumulation of $\mathrm{H}^{+}$ions derived from the accumulated NADH, which serves to inhibit PFK activity (10, 11). Thus, glycolysis can never completely substitute for mitochondrial oxidation, although its stimulation can supplement oxidative phosphorylation under conditions of partial oxygen debt.

Cerebral hypoxia-ischemia severe enough to produce irreversible tissue injury is always associated with major pertubations in the energy status of the brain $(3,12,13)$. Alterations occur not only in the adenine nucleotides but also in $\mathrm{PCr}$, which changes actually precede those of ATP, ADP, and AMP. These pertubations have been well-characterized in an experimental model of perinatal hypoxic-ischemic brain damage, developed in our laboratory (14). In this model, 7-d postnatal rats are subjected to unilateral common carotid artery ligation followed by exposure to hypoxia with $8 \%$ oxygen, an insult that produces permanent injury to the cerebral hemisphere ipsilateral to the carotid artery occlusion in the vast majority of animals. During hypoxiaischemia, changes in the tissue concentrations of the high-energy phosphate reserves occur early during the course of the metabolic insult and persist well into the recovery period $(15,16)$. As expected, greater depletions in PCr occur relative to ATP as the cell attempts to maintain optimal levels of ATP through the CPK equilibrium reaction driven also by the accumulation of ADP and $\mathrm{H}^{+}$ions (Fig. 1). With the eventual decline in tissue ATP, ADP and AMP accumulate in proportion to the loss of ATP. Ultimately, the total adenine nucleotide pool (ATP + ADP + AMP) also decreases, as AMP is catabolized slowly to adenosine and further breakdown products. The concentrations of ATP and the total adenylate compounds never completely recover after resuscitation, and their persisting partial depletions reflect the presence and severity of tissue destruction (16).

Of necessity, the loss of cellular ATP during hypoxia-ischemia severely compromises those metabolic processes that require energy for their completion. Thus, ATP-dependent $\mathrm{Na}^{+}$extrusion through the plasma membrane in exchange for $\mathrm{K}^{+}$is curtailed with a resultant intracellular accumulation of $\mathrm{Na}^{+}$and $\mathrm{Cl}^{+}$ as well as water (cytotoxic edema). Equally vital to cellular

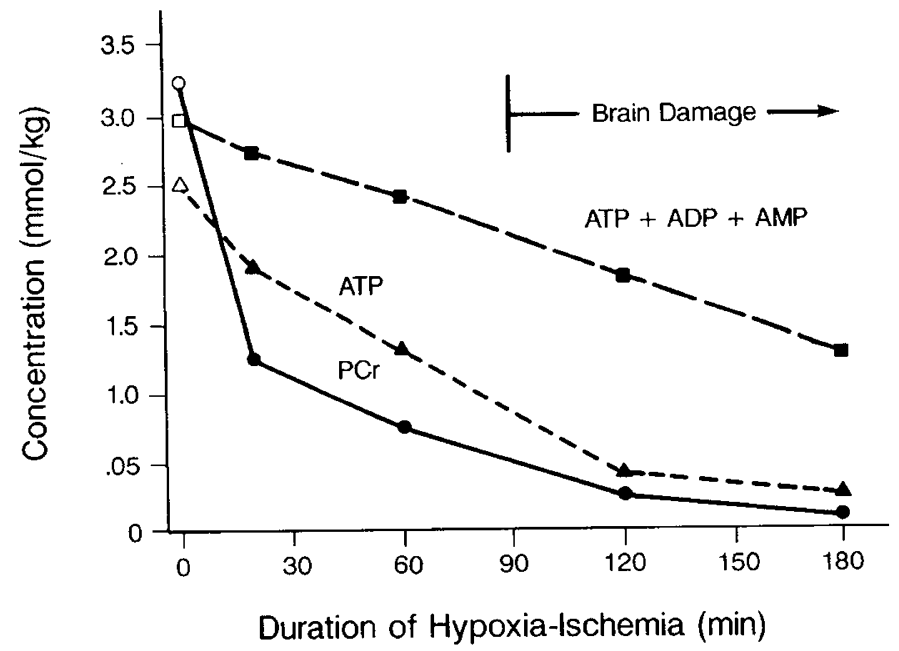

Fig. 1. Changes in cerebral high-energy phosphate reserves during hypoxia-ischemia in the immature rat. Seven-d postnatal rats were subjected to unilateral common carotid artery ligation followed by exposure to hypoxia with $8 \%$ oxygen at $37^{\circ} \mathrm{C}(14)$. Symbols represent means for ATP, PCr, and total adenine nucleotides (ATP + ADP + AMP). All values are significantly different from control (zero time point). Histologic brain damage commences after $90 \mathrm{~min}$ of hypoxia-ischemia, with increasing severity thereafter. Derived from data of Welsh et al. (15).

function is the prompt restoration of high-energy phosphate reserves during and after resuscitation. Without regeneration of ATP, endergonic reactions cannot resume, especially those involving ion pumping at plasma and intracellular membranes. Intracellular $\mathrm{Na}^{+}$and $\mathrm{Cl}^{+}$ions and water will continue to accumulate, and electrochemical gradients cannot be reestablished. Just how long the cell can survive under this situation is not known, but other factors are called into play that prominently influence ultimate cellular integrity.

The mechanism(s) by which ATP disruption persists into the recovery period relates to a lingering alteration in the function of mitochondria. In this regard, the pathologic studies of Brown and Brierley (17) and Brown (18) indicate that the earliest morphologic alteration of the neuron arising from hypoxiaischemia is a dilation of mitochondria with an accompanying separation of their cristae. Biochemical studies support the morphologic alterations to the extent that following hypoxia-ischemia in vitro analysis of mitochondria reveals a disturbance in substrate oxidation, suggesting an "uncoupling of oxidative phosphorylation" (19-21). It is assumed that reducing equivalents are oxidized in the presence of oxygen but ATP is not formed from the energy generated; such energy is consumed internally (not transferred to the cytosol) or is lost as heat. That oxidative phosphorylation is compromised after hypoxia-ischemia is confirmed also by studies that show that the brain can be well oxygenated concurrent with a persistent depletion in ATP (15, 22,23 ). The question remains as to what factors perpetuate the condition of uncoupled oxidative phosphorylation.

\section{FREE RADICAL FORMATION}

A free radical is an atom or molecule that contains an uneven number of electrons in its outer most orbit (24-26). The presence of an open or half bond renders the atom or molecule chemically reactive. A radical can react with another radical which eliminates both, or a radical can combine with a nonradical, the result of which is a new free radical. The latter characteristic enables free radicals to initiate and perpetuate chain reactions, the peroxidation of unsaturated fatty acids being a prominent example.

All biologic systems that consume (animals) or generate (plants) oxygen form free radicals $(6,25)$. For aerobic cells, oxygen-free radicals, i.e. $\left(\cdot \mathrm{O}_{2}^{-}\right)$, are produced in many oxidation- 
reduction reactions within the cytoplasm and also by electron transport within mitochondria. Once formed, $\mathrm{O}_{2}^{-}$reacts immediately with $\mathrm{H}^{+}$ions, derived from NADH or FADH, to produce $\mathrm{H}_{2} \mathrm{O}_{2}$ in the presence of the enzyme, superoxide dismutase. Metal ions, $\mathrm{Fe}^{+++}$and $\mathrm{Cu}^{++}$, promote the formation of highly reactive $\cdot \mathrm{OH}^{-}$:

$$
. \mathrm{O}_{2}^{-}+\mathrm{H}_{2} \mathrm{O}_{2} \rightarrow \mathrm{O}_{2}+\mathrm{OH}^{-}+\cdot \mathrm{OH}^{-}
$$

Other enzymes are present which protect cellular constituents from the oxidizing effect of $\mathrm{H}_{2} \mathrm{O}_{2}$; these enzymes include endoperoxidase and catalase. Thus:

$$
\begin{gathered}
\mathrm{H}_{2} \mathrm{O}_{2}+\mathrm{RH}_{2} \stackrel{\text { peroxidase }}{\longrightarrow} 2 \mathrm{H}_{2} \mathrm{O}+\mathrm{R} \\
\mathrm{H}_{2} \mathrm{O}_{2}+\mathrm{H}_{2} \mathrm{O}_{2} \stackrel{\text { catalase }}{\longrightarrow} 2 \mathrm{H}_{2}+\mathrm{O}_{2}
\end{gathered}
$$

Additional defenses against the potential-damaging effect of free radicals are provided by endogenous scavengers; which include cholesterol, $\alpha$-tocopherol (vitamin E), ascorbic acid (vitamin $\mathrm{C}$ ), and thiol-containing compounds, notably glutathione. Thus, cells are capable of rapidly destroying free radicals, once formed, via both enzymatic and nonenzymatic quenching.

Oxygen-free radicals are generated during and after hypoxiaischemia in several ways (24-26). During partial ischemia when at least a small amount of oxygen is available to the tissue, the low oxygen concentration at the site of cytochrome oxidase will impede the acceptance of electrons, thereby liberating free radicals at more proximal steps. These oxygen-free radicals cannot be consumed further within mitochondria and "leak" out into the cytoplasm. Two other potential sources of oxygen-free radicals are as by-products in the synthesis of prostaglandins (Fig. 2) and of xanthine and uric acid during hypoxia-ischemia and upon reoxygenation of the tissue.

As mentioned previously, during the course of hypoxia-ischemia, the adenine nucleotides, ATP, ADP, and AMP, are partially depleted (Fig. 1) with the formation of adenosine, inosine, and hypoxanthine that accumulate in the tissue. Under aerobic conditions, hypoxanthine is converted to xanthine and hence to uric acid by the enzyme, xanthine dehydrogenase:

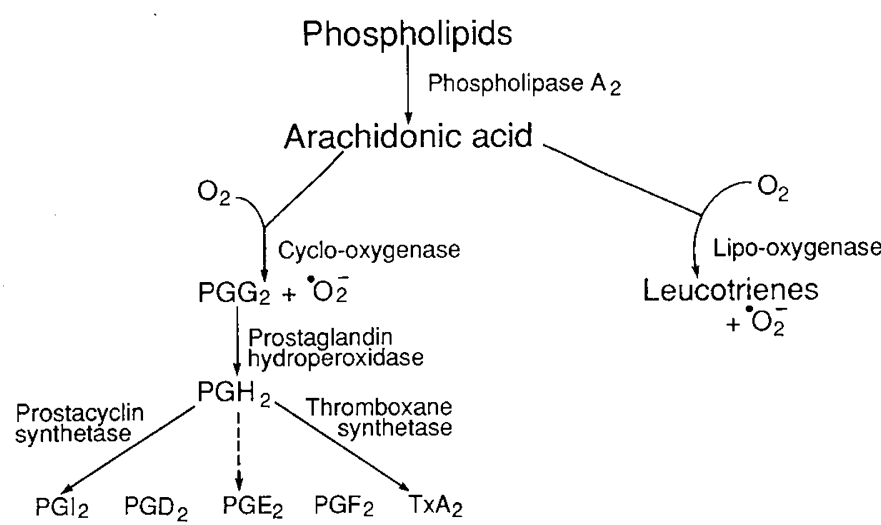

Fig. 2. Eicosanoid biosynthesis and oxygen-free radical formation. During hypoxia-ischemia, there is a rapid accumulation of free fatty acids (27-29), especially arachidonic acid, arising presumably from increased turnover of membrane phospholipids combined with a calciuminduced activation of phospholipase $\mathrm{A}_{2}$. Arachidonic acid stimulates the enzyme, cyclooxygenase, which catalyzes the formation of the prostaglandin intermediate, $\mathrm{PGG}_{2}$, in a reaction requiring oxygen and liberating . $\mathrm{O}_{2}{ }^{-}$. Once formed, $\mathrm{PGG}_{2}$ is converted to $\mathrm{PGH}_{2}$ by the action of prostaglandin hydroperoxidase. Other prostaglandins, notably prostacyclin $\left(\mathrm{PGI}_{2}\right)$ and thromboxane $\left(\mathrm{TxA}_{2}\right)$, also are formed via specific endoperoxidases with the generation of $\cdot \mathrm{O}_{2}{ }^{-}$. Finally, arachidonic acid also is the precursor of a class of compounds called leucotrienes, the formation of which involve hydroperoxidase and free radical production. xanthine

dehydrogenase

$$
\begin{aligned}
\text { hypoxanthine } & \stackrel{\text { xanthine }}{\text { xanthine }+\mathrm{H}_{2} \mathrm{O}} \\
& +\mathrm{NAD}^{+} \stackrel{\text { dehydrogenase }}{\longrightarrow} \text { uric acid }+\mathrm{NADH}+\mathrm{H}^{+}
\end{aligned}
$$

However, under the pathologic condition of hypoxia-ischemia, xanthine dehydrogenase is converted to xanthine oxidase through the activation of a specific protease by calcium. The oxidase uses molecular oxygen rather than $\mathrm{NAD}^{+}$upon reperfusion of the tissue, producing oxygen-free radicals:

\section{xanthine}

oxidase

hypoxanthine $\longrightarrow$ xanthine $+\mathrm{H}_{2} \mathrm{O}$
xanthine
$+\mathrm{O}_{2}^{-} \stackrel{\text { oxidase }}{\longrightarrow}$ uric acid $+2 \cdot \mathrm{O}_{2}{ }^{-}+2 \mathrm{H}^{+}$

The manner in which oxygen-free radicals cause or contribute to tissue injury presumably relates to their ability to attack the fatty acid moiety of cellular membranes $(13,25,26)$. Polyunsaturated fatty acids seem especially prone to peroxidative attack by free radicals that initiate and perpetuate chain reactions within the hydrophobic core of the lipid bilayer leading ultimately to membrane fragmentation. The chain reaction is promoted by excessive concentrations of intracellular free fatty acids and calcium ions.

Although there is evidence to support the concept of free radical-induced injury of many organs, including liver, lung, and the myocardium (26-30), the role of oxygen-free radicals in the genesis of hypoxic-ischemic brain damage remains controversial (31). In dependent investigations, Chan et al. (32) and Patt et al. (33) have shown an association between xanthine oxidase activity or $\mathrm{H}_{2} \mathrm{O}_{2}$ concentrations in brain and the vasogenic edema that precedes or accompanies hypoxic-ischemic cerebral infarction. Xanthine oxidase is confined largely to the endothelium of brain capillaries (34). Increased activity of the enzyme during and after hypoxia-ischemia might enhance free radical formation; leading, in turn, to endothelial disruption, breakdown of the blood-brain barrier and the formation of vasogenic edema with its deleterious effect on neuronal and glial integrity.

Presently, there is little information available regarding the relationship between free radical formation and perinatal hypoxic-ischemic brain damage. Armstead et al. (35) have demonstrated the appearance of oxygen-free radicals in the perfused subarachnoid space (cranial window technique) of newborn piglets after total cerebral ischemia. However, the extent of free radical generation was not correlated with the presence of brain damage in these animals. Rosenberg et al. (36) recently have shown that pretreatment of newborn sheep with superoxide dismutase and catalase, enzymes that promote the breakdown of $\mathrm{H}_{2} \mathrm{O}_{2}$ to inactive compounds, prevents the secondary hypoperfusion of the brain that follows asphyxia. As in the study of Armstead et al. (35), the preservation of cerebral perfusion after hypoxia-ischemia was not correlated with any amelioration of brain damage in these animals, because neuropathologic studies were not conducted in parallel with the physiologic investigations.

Indirect evidence of a role for oxygen-free radicals in perinatal hypoxic-ischemic brain damage is derived from the investigation of Palmer et al. (37) in immature rats. These investigators injected 7-d postnatal rats with the xanthine oxidase inhibitor, allopurinol, $30 \mathrm{~min}$ before the onset of hypoxia-ischemia. The results indicated that the allopurinol-treated animals exhibited less severe cerebral edema at $42 \mathrm{~h}$ of recovery compared to salinetreated control littermates. Chronic neuropathologic alterations also were less severe in the allopurinol-treated rats. Only two of 

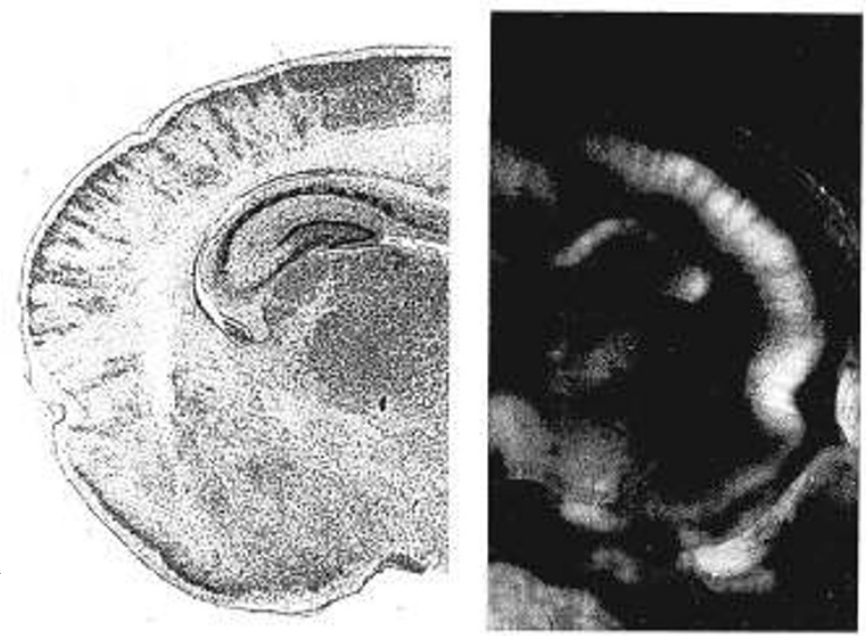

Fig. 3. Coronal section of immature rat brain showing alterations in NADH fluorescence (right) during hypoxia-ischemia and histologic alterations (left $)$ at $24 \mathrm{~h}$ of recovery. Seven-d postnatal rats were subjected to unilateral common carotid artery ligation followed by hypoxia with $8 \%$ oxygen (14). During hypoxia-ischemia, the rat brains were frozen in situ and coronal sections illuminated with UV light $(366 \mathrm{~nm})$; the fluorescent image $(450 \mathrm{~nm})$ then was recorded photographically (15). Note the columnar pattern of NADH fluorescence (lighter areas) in cerebral cortex and the enhanced fluorescence in the CA1 and CA3 sectors of the hippocampus, which correspond closely to the distribution of selective neuronal necrosis seen histologically (14).
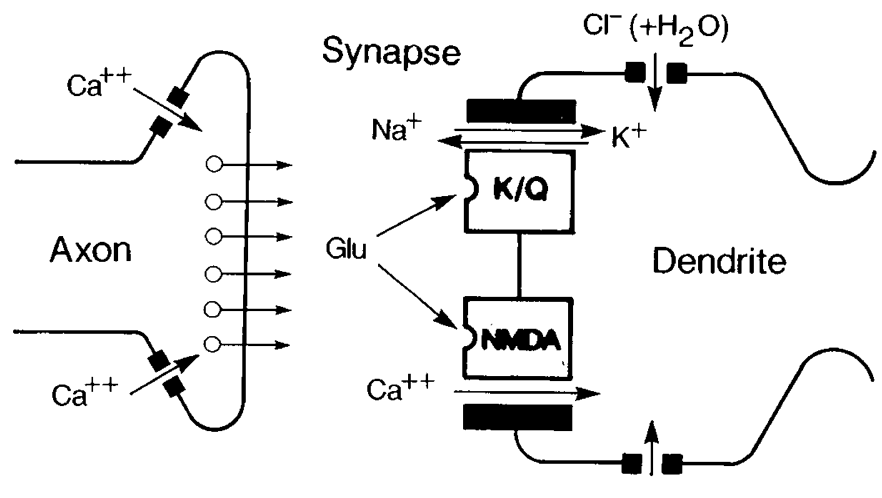

$$
\mathrm{Cl}^{-}\left(+\mathrm{H}_{2} \mathrm{O}\right)
$$

Fig. 4. Schematic representation of the cell surface glutamate receptor. Two separate channels have been proposed to be gated by the subtypes of the glutamate receptor; one for monovalent ions $\left(\mathrm{Na}^{+}\right.$in; $\mathrm{K}^{+}$ out) gated by kainate $(K)$ and quisqualate $(Q)$ receptors, and one allows predominantly $\mathrm{Ca}^{++}$entry into cells, gated by NMDA receptor. Despite the fact that the $\mathrm{Ca}^{++}$channel is agonist-operated, it can be blocked by $\mathrm{Mg}^{++}$in a voltage-dependent manner. Depolarization reverses the block, whereupon glutamate activation of the receptor leads to $\mathrm{Ca}^{++}$influx. Glycine, although an inhibitory neurotransmitter in spinal cord, appears to potentiate the action of glutamate at the NMDA receptor in brain. Thus, glutamate secretion from the nerve terminal into the synaptic cleft leads ultimately to $\mathrm{Ca}^{++}$entry into adjacent neurons by a sequential mechanism initiated by activation of the K/Q receptor leading to $\mathrm{Na}^{+}$/ $\mathrm{K}^{+}$exchange; which, in turn, depolarizes the membrane with secondary activation of the NMDA receptor and $\mathrm{Ca}^{++}$influx. From Siesjö and Bengtsson (62), with permission.

13 brains from the allopurinol group sustained gross infarction compared to 10 of 14 brains of the saline-treated animals. The findings indicate that allopurinol is beneficial in reducing the severity of perinatal hypoxic-ischemic brain damage, mediated either by the drug's inhibition of xanthine oxidase activity or via its role as a free radical scavenger.

\section{CELLULAR ACID-BASE STATUS}

Hypoxia-ischemia of a degree sufficient to produce neuronal injury is always associated with an increase in cerebral lactate concentrations and an associated decrease in tissue $\mathrm{pH}(12,13$, 25 ). The cellular lactacidosis results from a shift in glucose utilization from oxidative metabolism to partial or total anaerobic glycolysis. The question remained as to whether or not lactacidosis causes or contributes to neuronal injury, when Myers and Yamaguchi (38) demonstrated in juvenile monkeys that the brain damage that arises from cardiopulmonary arrest is influenced by the nutritional status of the animal. Specifically, monkeys fasted before cerebral ischemia exhibited far less brain damage than animals that received an i.v. infusion of glucose before arrest. Myers (39) attributed the difference in neuropathologic outcome to a varying degree of cerebral lactacidosis in the two groups, the fasted animals having substantially lower tissue lactate levels than either the fed or glucose-infused animals. Controlled studies from several other research laboratories have confirmed and extended the original observation that glucose pretreatment of mature animals accentuates hypoxic-ischemic brain damage $(40,41)$. Indeed, Pulsinelli et al. (41) have demonstrated that glucose supplementation of rats subjected to severe forebrain ischemia converts selective neuronal necrosis into infarction. Clinical studies in adult stroke patients also support the notion that hyperglycemia accentuates ischemic neuronal injury (42).

The pathophysiologic mechanism by which glucose accentuates brain damage has been attributed to excessive production of tissue lactic acid or to an associated derangement in $\mathrm{pH}$ homeostasis $(39,43-45)$. Some investigators have suggested that brain lactacidosis enhances hypoxic-ischemic injury in vulnerable regions and that a minimum concentration of 15 to $20 \mathrm{mmol}$ lactate $/ \mathrm{kg}$ brain wt is required for irreversible injury to occur $(39,43,44)$. Presumably, excessive lactate production during hyperglycemic cerebral hypoxia-ischemia relates to a greater acceleration of anaerobic glycolytic flux than that which occurs when the circulating glucose concentration is not increased.

From the perinatal point of view, the proposal that hyperglycemia accentuates hypoxic-ischemic brain damage is surprising, because research conducted many years ago demonstrated that pretreatment of perinatal animals with glucose prolongs their survival when subjected to systemic hypoxia or asphyxia (2) and may reduce permanent brain damage as well $(46,47)$. The mechanism underlying the hypoxic-anoxic resistance of perinatal animals rendered hyperglycemic is a prolongation of respiratory effort (gasping) combined with improved cardiovascular function $(46,48,49)$. Thus, glucose appears to have a paradoxical role in hypoxia-ischemia; prolonging hypoxic survival of immature animals on the one hand, and increasing brain damage in adults on the other.

To ascertain whether glucose is protective or deleterious to the perinatal brain undergoing hypoxia-ischemia, Voorhies et al. (50) devised a series of experiments in the immature rat. In a preliminary study, 7-d postnatal rats either were rendered hyperglycemic with $50 \%$ glucose or received a saline solution, after which they were exposed to the hypoxia produced by the inhalation of $8 \%$ oxygen. The glucose-supplemented rat pups survived more than twice as long as their normoglycemic littermates. Specifically, the duration of hypoxia for $\mathrm{LD}_{50}$ of the saline-treated animals was $3.5 \mathrm{~h}$ compared to an $\mathrm{LD}_{50}$ of $8 \mathrm{~h}$ for the glucosetreated rat pups.

In further experiments, glucose pretreated and control immature rats were exposed to cerebral hypoxia-ischemia for $2 \mathrm{~h}$, after which they were reared with their dams until $30 \mathrm{~d}$ of postnatal age. Neuropathologic analysis at that time failed to reveal any quantitative difference in the extent of brain damage in the glucose and saline-treated groups. The finding indicates that, unlike adults, glucose supplementation and its associated hyperglycemia in the immature animal does not accentuate the severity 


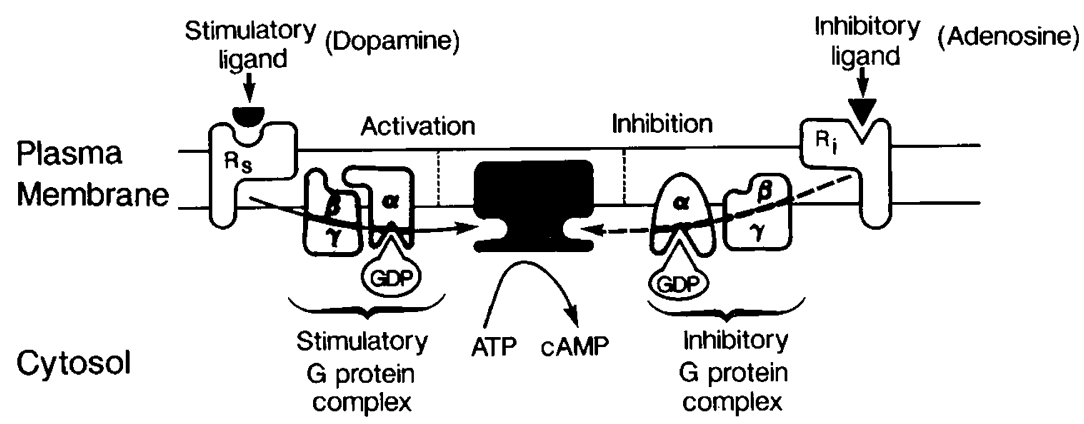

Fig. 5. Schematic representation of the adenylate cyclase signal transduction system. The adenylate cyclase activation system involves a series of reactions within the matrix of the plasma membrane, beginning with a specific receptor at the cell surface. When the receptor is stimulated, i.e. by dopamine or norepinephrine, a secondary, membrane-bound protein (so-called $\mathrm{G}_{\mathrm{s}}$ protein) is activated; which, in turn, stimulates the conversion of GDP to GTP. The GTP-G $\mathrm{G}_{\mathrm{s}}$ protein complex stimulates adenylate cyclase activity, which drives the reaction:

$$
\mathrm{ATP} \rightarrow \mathrm{cAMP}+\mathrm{PP}
$$

The final product is cyclic AMP, a second messenger that modulates several biochemical reactions within the cell, including glycogen synthesis (inhibition) and glycogenolysis (stimulation). The production of cAMP continues until the original transmitter (ligand) is dissociated from its receptor, at which time the $\mathrm{G}_{\mathrm{s}}$ protein assumes its original configuration and GDP is regenerated. Inhibitory $\mathrm{G}$ proteins $\left(G_{i}\right)$ also exist, which are activated by receptors different from those which activate $G_{s}$ protein, and which serve to inhibit adenylate cyclase activity. Courtesy of $S$. J. Vannucci.

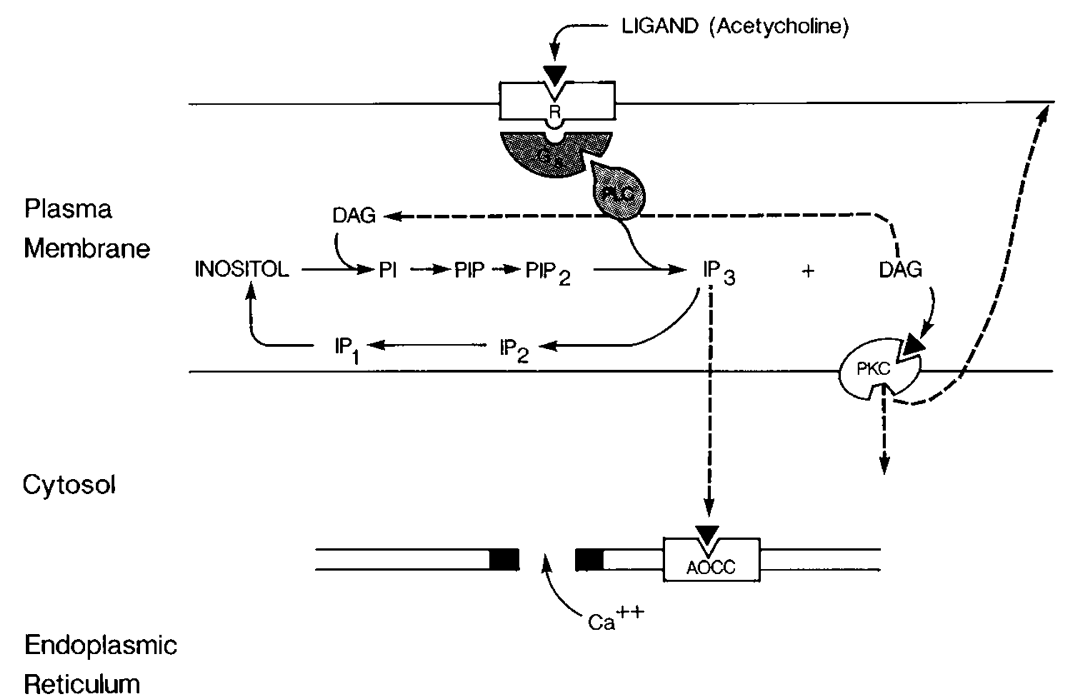

Fig. 6. Schematic representation of the phosphoinositide cycle. The phosphoinositide second messenger system involves the biologic turnover of phospholipids within the plasma membrane $(85,86)$. According to currently accepted concepts, neurotransmitter (e.g. acetylcholine or glutamate) interaction with a membrane receptor triggers the activation of phospholipase $\mathrm{C}(P L C)$, possibly acting through a specific $\mathrm{G}$ protein, to hydrolyze the membrane phospholipid, phosphatidylinositol-4,5-bisphosphate $\left(P I P_{2}\right)$. The products of the hydrolysis are $\mathrm{IP}_{3}$ and $\mathrm{DAG}$, both of which serve second messenger functions. Thereafter, additional reactions ultimately form inositol that condenses with DAG to regenerate PIP ${ }_{2}$, thereby completing the cycle. The second messenger functions of $\mathrm{IP}_{3}$ and DAG are undergoing intense investigation (88). The primary role of $\mathrm{IP}_{3}$, a highly charged, water-soluble compound, appears to be the release of $\mathrm{Ca}^{++}$from sequestered stores into the cytosol. In contrast, DAG is highly lipophilic and remains within the plasma membrane where it binds to activate protein kinase $\mathrm{C}(P K C) . \mathrm{Ca}^{++}$is also required for PKC activation. PKC stimulation affects a wide range of physiologic responses, including neurotransmitter release, synaptic sensitivity, and cellular contractility as well as feedback regulation of the phosphoinositide cycle.

of brain damage over that seen in the normoglycemic animal subjected to the same duration of hypoxia-ischemia.

The mechanism for the production of more extensive brain damage in glucose treated adult but not immature animals required clarification. One explanation might relate to the agespecific difference in the rate of cerebral glucose uptake and metabolism. In the newborn animal, the carrier that transports glucose from blood into brain is immature. Under normoxic conditions, glucose penetrates newborn rat brain at one-fifth the rate of adult rat brain (51). Therefore, it would be anticipated that during hypoxia in immature animals, brain glucose concentrations after glucose supplementation would be minimally increased over that of normoglycemic animals (52). In addition to a relative decrease in glucose transport across the blood-brain barrier, the immature brain has a lower rate of glucose utilization compared with the adult. During normoxia, cerebral glucose utilization and energy consumption for the 7-d postnatal rat is approximately one-tenth that of the adult $(11,53)$. Therefore, a less pronounced acceleration in glycolytic flux during hypoxia would be anticipated in the perinatal animal relative to the adult; this blunting of anaerobic glycolytic activity, in turn, would result in less tissue lactacidosis and less ultimate brain damage (52). It follows that glucose supplementation in the perinatal animal would minimally influence the extent of hypoxic-ischemic brain damage.

As mentioned previously, the proposed biochemical mechanism responsible for the deleterious effect of glucose on the brains of adult animals during hypoxia-ischemia relates to an excessive accumulation of tissue lactic acid or to an associated derangement in $\mathrm{H}^{+}$ion homeostasis. Indeed, numerous investi- 


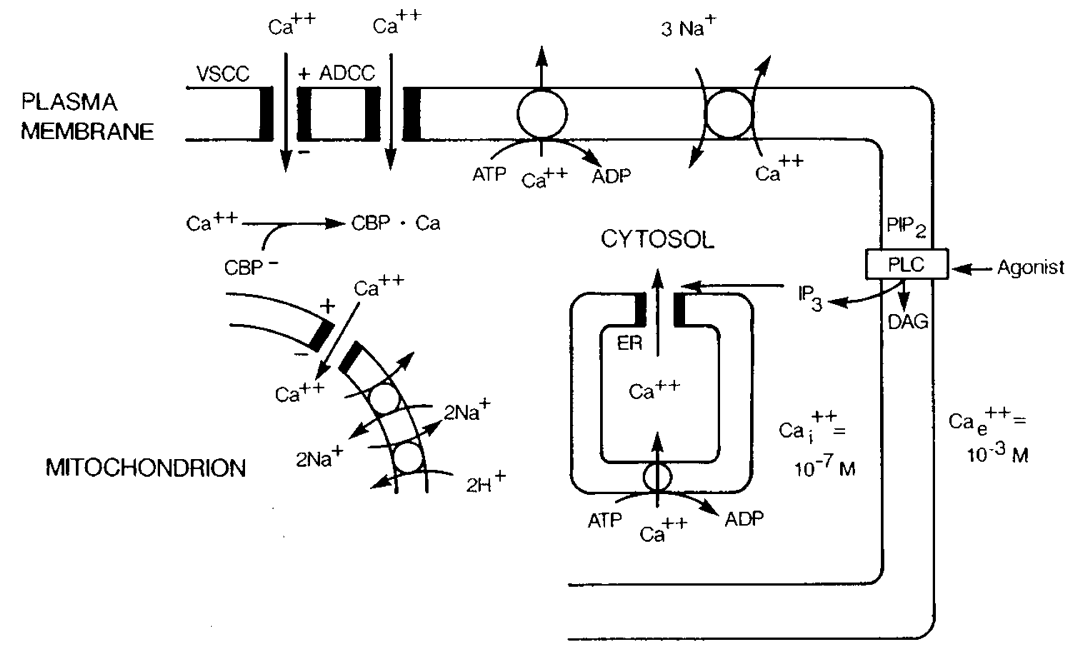

Fig. 7. Transcellular and intracellular calcium fluxes. $\mathrm{Ca}^{++}$influx from the extracellular space to the cytosol occurs via both VSCC and AOCC. $\mathrm{Ca}^{++}$efflux from the cytosol to the extracellular fluid occurs via an energy-dependent uniport system and an antiport system involving $\mathrm{Na}^{+}$. Intracellular $\mathrm{Ca}^{++}$sequestration occurs primarily within mitochondria and the $\mathrm{ER}$. $\mathrm{Ca}^{++}$is also bound via specific calcium-binding proteins $\left(\mathrm{CBP}^{-}\right)$. $\mathrm{Ca}^{++}$release from the ER occurs upon stimulation by $\mathrm{IP}_{3}$, whereas $\mathrm{Ca}^{++}$release from mitochondria involves an antiport system with $\mathrm{Na}^{+}$, influenced by $\mathrm{H}^{+}$. Modified from Siesjö and Bengtsson (62), with permission.

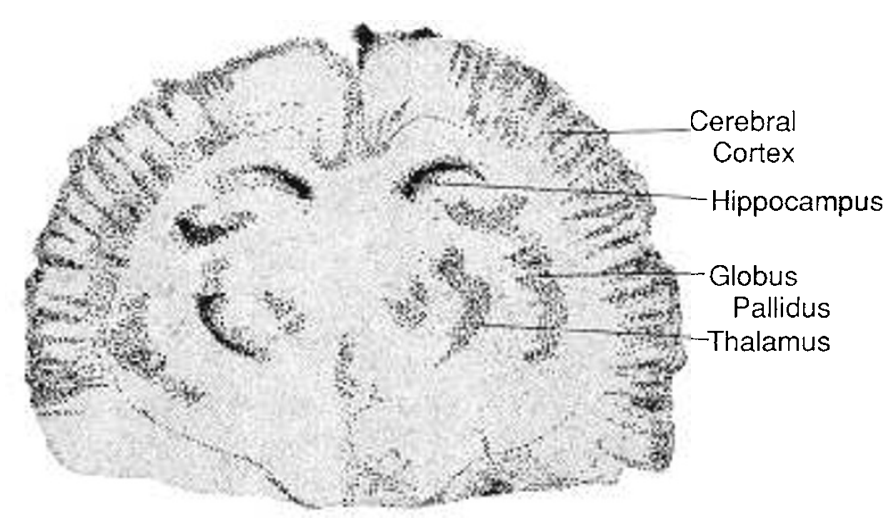

Fig. 8. Schematic representation of a coronal section of immature rat brain showing radioactive calcium accumulation during hypoxia-ischemia. Seven-d postnatal rats were subjected to hypoxia-ischemia (14), before which they received an s.c. injection of $\left[{ }^{45} \mathrm{Ca}\right] \mathrm{Cl}_{2}$. During hypoxiaischemia, their brains were prepared for ${ }^{45} \mathrm{Ca}$ autoradiography. Radioactivity (darker areas) is prominent in cerebral cortex as columns perpendicular to the pial surface. Radioactivity also is seen in the CA1 and CA3 sectors of hippocampus, in the lateral regions of the thalamus, and in globus pallidus. Note the similarity of the calcium distribution to that of NADH fluorescence during hypoxia-ischemia and histologic alterations at $24 \mathrm{~h}$ of recovery (Fig. 3).

gations in adult animals have demonstrated a direct correlation between the level of circulating glucose during hypoxia-ischemia and the extent of lactate accumulation in brain $(39,44,45,54)$. Furthermore, the more severe the lactacidosis, the more profound the blood flow and metabolic alterations that occur after cessation of the insult $(44,54)$, portending greater ultimate brain damage. However, investigations in immature rats tend to refute the notion that lactacidosis plays a critical role in determining the presence and extent of tissue injury, at least in perinatal animals. In the model of hypoxic-ischemic brain damage in the immature rat, widespread infarction and edema are confined to one cerebral hemisphere that is ipsilateral to the common carotid artery occlusion (14). In metabolic studies, conducted in parallel with the original neuropathologic investigation, lactate concentrations in the cerebral hemisphere destined to be damaged were always less than $18 \mathrm{mmol} / \mathrm{kg}$ and were usually in the range of $10-14 \mathrm{mmol} / \mathrm{kg}$ (13/14 brains) (15). Furthermore, lactate in the ischemic hemisphere never exceeded by more than $4 \mathrm{mmol} / \mathrm{kg}$ the accumulated lactate in the contralateral, nonischemic hemisphere; and the difference between the two sides was usually less than $2 \mathrm{mmol} / \mathrm{kg}$ (nine/14 brains). The relative uniformity of lactate accumulation in the two cerebral hemispheres, only one of which ultimately shows ischemic change, suggests that lactic acid per se is not the primary factor causing tissue injury.

It must be emphasized that hypoxia-ischemia leads to cellular acidosis via sources of $\mathrm{H}^{+}$ions in addition to lactic acid. Possibly the major origin of reducing equivalents is NADH $\left(+\mathrm{H}^{+}\right)$which accumulates during cellular oxygen debt (55). In this regard, Welsh et al. (15) examined the redox state of immature rat brain undergoing hypoxia-ischemia by a technique of reflectance fluorometry. Alterations in regional fluorescence, representing the intracellular accumulation of NADH $(56,57)$, were prominent in cerebral cortex and the CAl sector of the hippocampus (Fig. 3). A columnar pattern of NADH fluorescence was apparent in neocortex, which mimicked closely the distribution of neuronal necrosis seen in this model of perinatal brain injury. The close correspondence between altered NADH fluorescence and neuropathologic outcome suggests an important role for intracellular acidosis in the pathogenesis of hypoxic-ischemic brain damage, albeit not necessarily lactacidosis.

\section{EXCITATORY NEUROTRANSMITTERS}

To maintain brain function normal requires a delicate balance between excitatory and inhibitory neurotransmitter activity. Well-established excitatory neurotransmitters include acetylcholine and the monoamines, dopamine, norepinephrine, and serotonin; whereas transmitters known to inhibit neuronal activity include $\gamma$-aminobutyric acid and glycine. There is evidence that the amino acid, glutamate, also functions as an endogenous excitatory neurotransmitter $(58,59)$.

The manner in which glutamate exerts its action on neurons recently has been elucidated. The presence of specialized receptors responsive to glutamate have been identified in specific regions of immature and adult brain, including the middle layers of cerebral cortex, the striatum, and the CA1 sector of the hippocampus $(60,61)$. Investigations have shown that at least three membrane receptors can be activated by glutamate; they are named after derivatives that individually excite them: kainate, quisqualate, and NMDA (Fig. 4). These receptors subserve agonist-operated channels, through which ions can pass independent of the electrochemical (voltage) gradient across the plasma membrane $(59,62)$. 


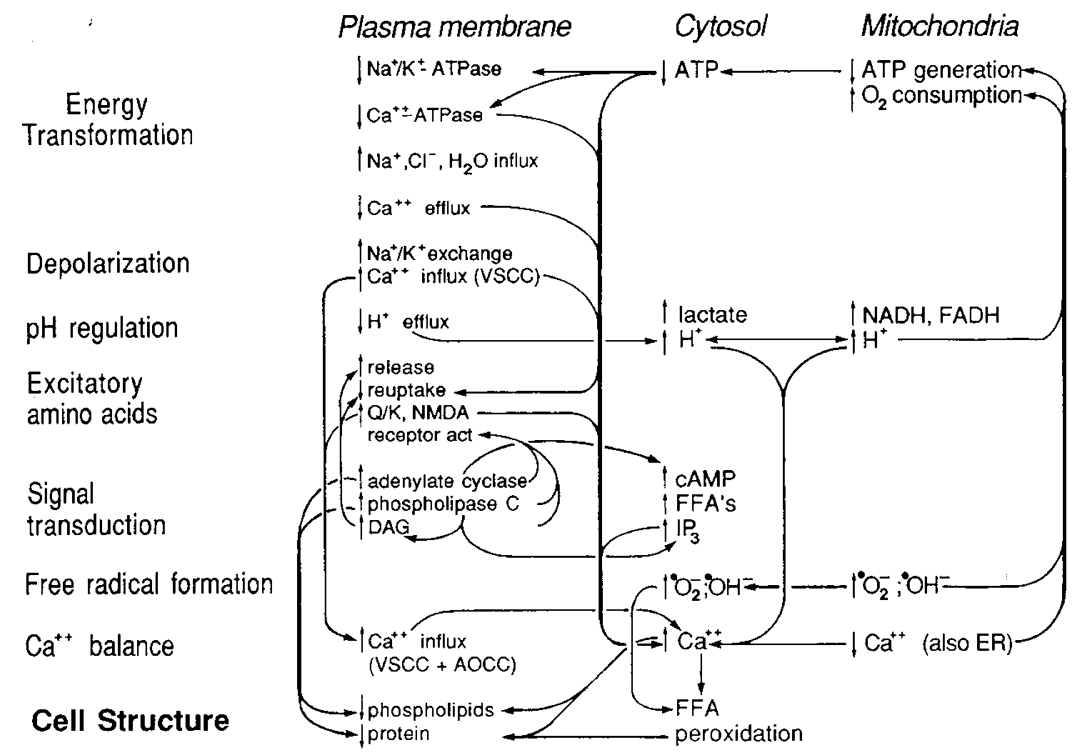

Fig. 9. Interrelationships between cellular and molecular events leading to hypoxic-ischemic brain damage. Hypoxia-ischemia or ischemia alone sets in motion a cascade of biochemical events commencing with a shift from oxidative to anaerobic metabolism, which leads to an accumulation of $\mathrm{NADH}, \mathrm{FADH}$, and lactic acid plus $\mathrm{H}^{+}$ions. Anaerobic glycolysis cannot keep pace with cellular energy demands, resulting in a depletion of high-energy phosphate reserves, including ATP. Transcellular ion pumping fails, leading to an accumulation of intracellular $\mathrm{Na}^{+}, \mathrm{Ca}^{++}, \mathrm{Cl}^{-}$, and $\mathrm{H}_{2} \mathrm{O}$ (cytotoxic edema). Hypoxia-ischemia also stimulates release of excitatory amino acids (glutamate) from axon terminals, enhanced by DAG activation of protein kinase $C$. The glutamate release, in turn, activates kainate/quisqualate (K/Q) and NMDA cell surface receptors, resulting in an influx of $\mathrm{Na}^{+}$and $\mathrm{Ca}^{++}$ions. Within the cytosol, free fatty acids (FFA) accumulate from increased membrane phospholipid turnover and thereafter undergo peroxidation by oxygen-free radicals that arise from reductive processes within mitochondria and as by-products in the synthesis of prostaglandins, xanthine, and uric acid. $\mathrm{Ca}^{++}$ions accumulate within the cytosol as a consequence of increased plasma (cellular) membrane influx via VSCC and AOCC and of decreased efflux across the plasma membrane combined with release from mitochondria and the ER; the latter process is stimulated by $\mathrm{IP}_{3}$. The combined effects of cellular energy failure, acidosis, free radical formation, $\mathrm{Ca}^{++}$accumulation, and lipid peroxidation serve to disrupt structural components of the cell (phospholipids, proteins) with its ultimate death.

The proposal that glutamate is excitotoxic to neurons stems from investigations spanning 30 years. Lucus and Newhouse (63) showed that systemically administered glutamate is capable of damaging the retina of newborn mice, and several years later Olney (64) produced damage in developing mouse brain by subjecting the animals to a diet rich in glutamate. With this and other experiments, Olney (64) championed the "excitotoxic" nature of glutamate and its analogs. More recent in vitro and in vivo studies have confirmed the earlier experiments. Indeed, several lines of research implicate glutamate toxicity as a major factor in the production of hypoxic-ischemic injury of selectively vulnerable neurons, i.e. those nerve cells predominantly innervated by glutaminergic neurons. First, glutamate is directly toxic to mature neurons in culture (59). Second, neurons in culture and hippocampal slices die upon exposure to anoxia, but death can be prevented or attenuated by the presence of $\mathrm{Mg}^{++}$, which blocks NMDA receptors, or by glutamate antagonists (65-69). Third, direct injection of glutamate or glutamate agonists into specific regions of brain in vivo produces neuronal injury identical to that seen following hypoxia-ischemia $(70-72)$, to which the immature brain appears especially vulnerable $(73,74)$. Fourth, deafferentation of the glutaminergic excitatory input into the hippocampus reduces the damage produced by hypoxiaischemia (75). Finally, specific glutamate antagonists, including phencyclidine and MK-801, améliorate hypoxic-isćhemic brain damage in vivo (76-79). These studies provide convincing evidence that excessive exposure of neurons to glutamate, as occurs during hypoxia-ischemia $(80,81)$, leads to morphologic alterations characteristic of ischemic neuronal necrosis.

The role of excitatory neurotransmitters, and specifically glutamate, in the susceptibility of the immature brain to hypoxicischemic brain damage has undergone extensive investigation, predominantly by Silverstein and coworkers $(73,74)$. These investigators have shown that glutamate receptor agonists exhibit preferential toxic effects on specific regions (striatum and hip- pocampus) of brain that is dependent on the age of the animal. In the immature rat, the hierarchy of neurotoxicity is NMDA > quisqualic acid $>$ kainic acid, while that of the adult rat is kainic acid $>$ NMDA $\geq$ quisqualic acid. Furthermore, intracerebral injections of NMDA produces far greater damage of vulnerable neurons in immature rat brain than equivalent or larger doses of the analog in adult rat brain (74). These age-specific differences in the sensitivity of the brain to excitatory neurotransmitter toxicity presumably relates to developmental alterations in the density and distribution of glutamate receptor subtypes $(60,61)$, in glutamate binding to its receptors, or in transmembrane biochemical events (cation fluxes or signal transduction) initiated by receptor activation.

The mechanism by which excitatory amino acids exert their toxic effect has not been entirely clarified, but altered ion fluxes across the plasma membrane undoubtedly play a role $(62,82)$. Based primarily on their investigations in neuronal cell cultures, Rothman and Olney (59) have proposed two mechanisms of ionmediated neuronal injury. The first or early toxicity relates to glutamate-induced $\mathrm{Na}^{+}$influx into neurons during depolarization. Depolarization disturbs the intra-/extracellular balance of $\mathrm{Cl}^{-}$, and the anion flows down its electrochemical gradient into the cell. The entry of $\mathrm{Na}^{+}$and $\mathrm{Cl}^{-}$increases cell osmolality, necessitating the influx of water. Subcellular edema ensues, which if severe enough leads to lysis of the neuron. A delayed neurotoxicity also occurs, as has been observed in vivo in selected neurons of the hippocampus in immature and adult animals (79, $83,84)$. This delayed neuronal' necrosis presumably relates to excessive $\mathrm{Ca}^{++}$entry into the cell via NMDA receptor-mediated channels. Calcium, in turn, sets in motion a cascade of biochemical events that culminate in the death of the neuron.

\section{SIGNAL TRANSDUCTION AND SECOND MESSENGERS}

For hormones and neurotransmitters to influence intracellular metabolic processes requires a transfer of information from 
outside to inside the cell across the plasma membrane (signal transduction). One mechanism for the transfer of information is via specific ion channels. The other mechanism is via activation of membrane-bound protein receptors, whereupon reactions are initiated that ultimately lead to the production within the cytosol of a biochemically active substance (second messenger). At present, two major signal transduction systems are known to exist in brain; specifically, the adenylate cyclase and the phosphoinositide cycles (Figs. 5 and 6) $(6,85)$.

The extent to which signal transduction is altered during hypoxia-ischemia and the nature of its metabolic consequences have yet to be fully delineated. It has been known for several years that cAMP levels in brain increase during hypoxia-ischemia (87-89), suggesting an activation of the adenylate cyclase signal transduction system. More recent experiments have shown that phosphotidyl-inositol turnover also is stimulated during and after hypoxia-ischemia (90-92), resulting in the formation of inositol phosphates $\left(\mathrm{IP}_{3}\right.$ and $\left.\mathrm{DAG}\right)$ as well as the release of free fatty acids from membranes and their accumulation in the cytosol. The formation of $\mathrm{IP}_{3}$ stimulates $\mathrm{Ca}^{++}$release from intracellular stores; whereas DAG activates protein kinase C, which, in turn, stimulates the release of specific neurotransmitters, including glutamate, from nerve terminals (93). If unimpeded, the continued production of these second messengers would set in motion a vicious cycle of catabolic reactions ultimately devastating to cell integrity.

\section{CALCIUM HOMEOSTASIS}

Owing to its ubiquitous functions, $\mathrm{Ca}^{++}$is often considered an intracellular second messenger. The divalent cation is intimately involved as a cofactor in numerous cellular reactions, some of which have been discussed. Therefore, it is not surprising that a disruption of intracellular $\mathrm{Ca}^{++}$homeostasis has wide-ranging effects on neuronal metabolism and function.

Given the cation's strategic role in metabolic regulation, it is important that concentrations of $\mathrm{Ca}^{++}$are tightly regulated within the cell (Fig. 7). Indeed, it is likely that almost $100 \%$ of intracellular $\mathrm{Ca}^{++}$is bound within subcellular organelles and that free $\mathrm{Ca}^{++}$normally exists in very low concentrations $\left(<10^{-7} \mathrm{M}\right)$. This means that there is an enormous gradient for free $\mathrm{Ca}^{++}$ across the plasma membrane that tends to drive the ion into cells. The sites of intracellular $\mathrm{Ca}^{++}$binding include primarily mitochondria and the ER and to a lesser extent the nucleus and plasma membrane. Binding occurs by both energy-dependent (ATP) and independent processes that also is influenced by intracellular $\mathrm{pH}$. Lastly, specific $\mathrm{Ca}^{++}$-binding proteins, dispersed within the cytosol, serve to maintain free $\mathrm{Ca}^{++}$concentrations low $(6,25,62,94)$.

In addition to $\mathrm{Ca}^{++}$sequestration into subcellular organelles, the free cytosolic concentration of the cation is closely regulated by fluxes across the plasma membrane (Fig. 7). Specific ion channels for $\mathrm{Ca}^{++}$exist in all cells, which either are VSCC or AOCC at membrane receptors predominantly of the NMDA (glutamate) type. These channels allow for $\mathrm{Ca}^{++}$flux into the cell under conditions of membrane depolarization or receptor activation. A network of ion channels also exists for the extrusion of intracellular $\mathrm{Ca}^{++}$; these channels operate via either $\mathrm{Ca}^{++}$ ATPase or a $3 \mathrm{Na}^{+} / \mathrm{Ca}^{++}$exchange (antiport) system with energy derived from the transmembrane $\mathrm{Na}^{+}$gradient.

Under physiologic conditions, any rise in intracellular $\mathrm{Ca}^{++}$ occurring from entry via ion channels is rapidly reversed by its extrusion through the plasma membrane or its sequestration into subcellular organelles. Of the latter, the ER appears most important. $\mathrm{Ca}^{++}$binding to the ER occurs via an energy-dependent mechanism that involves ATP. $\mathrm{Ca}^{++}$release from the ER into the cytosol occurs in response to stimulation by $\mathrm{IP}_{3}$, a second messenger derived from the plasma membrane. $\mathrm{Ca}^{++}$sequestration by mitochondria involves a "uniport" mechanism that efficiently moves $\mathrm{Ca}^{++}$into the matrix of the organelle using energy stored in the voltage gradient across the inner membrane. $\mathrm{Ca}^{++}$release from mitochondria into the cytosol occurs via a pathway separate from the uptake system and probably involves $\mathrm{Na}^{+} / \mathrm{Ca}^{++}$exchange, influenced by the $\mathrm{H}^{+}$ion gradient across the membrane (Fig. 7).

Hypoxia-ischemia increased the free cytosolic concentration of $\mathrm{Ca}^{++}(95-97)$. It is presumed that the elevation arises from two sources, specifically, 1) release of intracellular stores and 2) increased influx (or decreased efflux) across the plasma membrane. The release of intracellular bound $\mathrm{Ca}^{++}$into the cytosol results from increased intracellular levels of $\mathrm{IP}_{3}$ influenced by cellular acidosis that promotes unbinding of $\mathrm{Ca}^{++}$from the microsomes of the ER. Additionally, increased extrusion and decreased entry of $\mathrm{Ca}^{++}$from and into mitochondria occur, owing to a change in the electrochemical gradient across the matrix membrane influenced also by acidosis. Increased $\mathrm{Ca}^{++}$ flux across the plasma membrane occurs in response to depolarization, opening VSCC, as well as to stimulation of NMDA receptor-operated $\mathrm{Ca}^{++}$channels $(\mathrm{AOCC}$ ) by glutamate. Finally, $\mathrm{Ca}^{++}$efflux through the plasma membrane is disrupted by the energy failure which accompanies hypoxia-ischemia, upon which $\mathrm{Ca}^{++}$-ATPase is dependent, and by a curtailment or even reversal of the $\mathrm{Na}^{+} / \mathrm{Ca}^{++}$antiport system. These events, occurring in concert, serve to increase free cytosolic $\mathrm{Ca}^{++}$to a potentially toxic level.

That cytosolic $\mathrm{Ca}^{++}$increases in both immature and adult brain during hypoxia-ischemia has been substantiated by several lines of research in animal models. Using the oxalate-pyroantimonate technique for the electron microscopic visualization of intracellular $\mathrm{Ca}^{++}$, Van Reempts and Borgers (98) showed that $\mathrm{Ca}^{++}$increases rapidly in neurons of adult rats during hypoxiaischemia, but the ion actually dissipates during the early recovery period. Thereafter, a secondary "calcium overload" ensues, which is associated with neuronal necrosis in the hippocampus. Dienel (99) injected $\left[{ }^{45} \mathrm{Ca}\right] \mathrm{Cl}_{2}$ into adult rats undergoing severe forebrain ischemia and found substantial uptake of radiolabeled $\mathrm{Ca}^{++}$into cerebral cortex, striatum, and hippocampus. These and other studies testify to the major alterations in cellular $\mathrm{Ca}^{++}$ balance that occur during cerebral hypoxia-ischemia.

Relevant to the immature brain, Stein and Vannucci (100) conducted experiments to ascertain the presence and extent of altered $\mathrm{Ca}^{++}$homeostasis in an experimental model of perinatal cerebral hypoxia-ischemia (14). Before and after hypoxia-ischemia in 7-d postnatal rats, the animals received a subcutaneous injection of $\left[{ }^{45} \mathrm{Ca}\right] \mathrm{Cl}_{2}$ and their brains were subjected to autoradiography at specific intervals for up to $15 \mathrm{~d}$ postinsult. During hypoxia-ischemia, calcium flux into brain was prominent in cerebral cortex, hippocampus, striatum, and thalamus. During the first $5 \mathrm{~h}$ of recovery, $\left[{ }^{45} \mathrm{Ca}\right] \mathrm{Cl}_{2}$ radioactivity in all brain regions was low but thereafter increased progressively over $72 \mathrm{~h}$. As during hypoxia-ischemia, the distribution of radioactivity was most prominent in those structures that are known to be vulnerable to hypoxic-ischemic injury (Fig. 8). The investigators concluded that hypoxia-ischemia is associated with enhanced calcium uptake into the immature brain, which temporarily dissipates, but then progressively accumulates during the recovery period. The findings implicate a disruption of intracellular $\mathrm{Ca}^{++}$ homeostasis as a major factor in the evolution of perinatal hypoxic-ischemic brain damage.

The mechanisms by which altered $\mathrm{Ca}^{++}$balance threatens the cell continues to be elucidated but undoubtedly relates to disturbances in those biochemical reactions subserved by $\mathrm{Ca}^{++}$. As mentioned previously, $\mathrm{Ca}^{++}$activates numerous intracellular reactions, the continued stimulation of which would compromise severely the viability of the neuron. Among these reactions include the activation of several lipases, proteases, and endonucleases, all of which attack the structural integrity of the cell. Important also is the continued activation of phospholipase $\mathrm{C}$ which promotes a progressive breakdown in the phospholipid components of the plasma (and possibly subcellular) membrane. 
$\mathrm{Ca}^{++}$also contributes to the formation of oxygen-free radicals via the formation of xanthine and prostaglandins; such radicals are capable of peroxidizing the free fatty acid moiety of membranes. Finally, high concentrations of intracellular free $\mathrm{Ca}^{++}$ lead to an uncoupling of oxidative phosphorylation within mitochondria, as the energy formed during recovery from hypoxiaischemia is immediately consumed in an attempt to reverse and then maintain the electrochemical (ion) gradient across the mitochondrial membrane. This "futile" cycling of ions restricts the production and transfer of ATP into the cytosol to be used for structural repair and the reestablishment of ionic gradients across the plasma membrane. Taken together, the toxic effects of excessive $\mathrm{Ca}^{++}$accumulation are adequate to cause membrane desintegration and the death of the neuron. Thus, altered calcium homeostasis may represent the "final common pathway" not only for hypoxia-ischemia but for other forms of acute brain damage as well (28).

\section{SYNOPSIS}

The preceding sections attest to the complexity of the biologic processes that operate to maintain neuronal function and how these processes are compromised during and after hypoxia-ischemia. An intimate relationship exists among those mechanisms that serve to control cellular homeostasis; therefore, it is not surprising that multiple systems fail when hypoxia-ischemia exceeds the threshold of biochemical and morphologic reversibility (Fig. 9). An excessive accumulation of intracellular $\mathrm{Ca}^{++}$may be the critical factor that determines whether or not death of the neuron ultimately occurs. Further research is required to confirm or deny the key role of $\mathrm{Ca}^{++}$in initiating neuronal necrosis and how the process can be prevented, or at least retarded, through therapeutic intervention.

\section{REFERENCES}

1. Vannucci RC 1978 Neurologic aspects of perinatal asphyxia. Pediatr Ann 7:15-30

2. Vannucci RC, Plum F 1975 Pathophysiology of perinatal hypoxic-ischemic brain damage. In: Gaull GE (ed) Biology of Brain Dysfunction, Vol. 3. Plenum Publishing Corp, New York, pp 1-45

3. Siesjö BK 1978 Brain Energy Metabolism. Wiley, Chichester, England

4. Erecińska M, Silver IA 1989 ATP and brain function. J Cereb Blood Flow Metab 9:2-19

5. Vannucci RC 1990 Perinatal brain metabolism. In: Polin RA, Fox WW (eds) Neonatal and Fetal Medicine. Grune and Stratton (in press)

6. Alberts B, Bray D, Lewis J, Raff M, Roberts K, Watson JD 1983 Molecular Biology of the Cell. Garland Publishing, Inc, New York

7. Hawkins R 1985 Cerebral energy metabolism. In: McCandless DW (ed) Cerebral Energy Metabolism and Metabolic Encephalopathy. Plenum Press, New York, pp 3-33

8. Sugano T, Oshino N, Chance B 1974 Mitochondrial functions under hypoxic conditions: the steady state of cytochrome $\mathrm{c}$ reduction and energy metabolism. Biochim Biophys Acta 347:340-358

9. LaManna JC, Light AI, Peretsman SJ, Rosenthal M 1984 Oxygen insufficiency during hypoxic hypoxia in rat brain cortex. Brain Res 293:312-318

10. Lowry OH, Passonneau JV, Hasselberger FX, Schulz DW 1964 Effect of ischemia on known substrates and cofactors of the glycolytic pathway in brain. J Biol Chem 239:18-30

11. Duffy TE, Kohle SJ, Vannucci RC 1975 Carbohydrate and energy metabolism in perinatal rat brain: relation to survival in anoxia. J Neurochem 24:271276

12. Hossmann K-A 1982 treatment of experimental cerebral ischemia. J Cereb Blood Flow Metabol 2:275-297

13. Raichle ME 1983 The pathophysiology of brain ischemia. Ann Neurol 13:210

14. Rice JE, Vannucci RC, Brierley JB 1981 The influence of immaturity on hypoxic-ischemic brain damage in the rat. Ann Neurol 9:131-141

15. Welsh FA, Vannucci RC, Brierley. JB 1982 Columnar alterations of NADH fluorescence during hypoxia-ischemia in immature rat brain. J Cereb Blood Flow Metabol 2:221-228

16. Palmer C, Brucklacher RM, Christensen MA, Vannucci RC 1990 Carbohydrate and energy metabolism during the evolution of hypoxic-ischemic brain damage in the immature rat. J Cereb Blood Flow Metabol (in press)

17. Brown AW, Brierley JB 1973 The earliest alterations in rat neurones and astrocytes after anoxia-ischemia. Acta Neurophatol 23:9-22

18. Brown AW 1977 Structural abnormalities in neurones. J Clin Pathol 30(Suppl II): $155-169$

19. Rehncroná S, Mela L, Siesjö BK 1979 Recovery of brain mitochondrial function in the rat after complete and incomplete cerebral ischemia. Stroke 10:437-446

20. Linn F, Paschen W, Grosse Ophoff B, Hossmann K-A 1987 Mitochondrial respiration during recirculation after prolonged ischemia in cat brain. Exp Neurol 96:321-333

21. Sims NR, Pulsinelli WA 1987 Altered mitochondrial respiration in selectively vulnerable brain subregions following transient forebrain ischemia in the rat J Neurochem 49:1367-1374

22. Kogure K, Busto R, Schwartzman RJ 1980 The dissociation of cerebral blood flow, metabolism and function in the early stages of developing cerebral infarction. Ann Neurol 8:278-290

23. Dora E, Tanaka K, Greenberg JH, Gonatas NH, Reivich M 1986 Kinetics of microcirculatory NAD/NADH, and electrocorticographic changes in cat brain cortex during ischemia and recirculation. Ann Neurol 19:536-544

24. Butterfield JD, McGraw CP 1978 Free radical pathology. Stroke 9:443-445

25. Siesjö BK 1981 Cell damage in the brain: a speculative synthesis. J Cereb Blood Flow Metabol 1:155-185

26. McCord JM 1985 Oxygen-derived free radicals in postischemic tissue injury. N Engl J Med 312:159-163

27. Majewska M, Strosznajder J, Lazarewicz J 1978 Effect of ischemic anoxia and barbiturate anesthesia on free radical oxidation of mitochondrial phospholipids. Brain Res 158:423-434

28. Rehncroná S, Westerberg E, Akesson B, Siesjö BK 1978 Brain cortical fatty acids and phospholipids during and following complete and severe incomplete ischemia. Stroke 9:327-335

29. Bhakoo K, Crockard HA, Lascelles PT 1984 Regional studies of changes in brain fatty acids following experimental ischaemia and reperfusion in the gerbil. J Neurochem 43:1025-1031

30. Saugstad OD 1988 Hypoxanthine as an indicator of hypoxia: Its role in health and disease through free radical production. Pediatr Res 32:143-150

31. Ginsberg MD, Watson BD, Busto R, Yoshida S, Prado R, Nakayama H Ikeda M, Dietrich WD, Globus MY- $\Upsilon 1988$ Peroxidative damage to cell membranes following cerebral ischemia: a cause of ischemic brain injury? Neurochem Pathol 9:171-194

32. Chan PH, Schmidley JW, Fishman RA, Longar SM 1984 Brain injury, edema and vascular permeability changes induced by oxygen-derived free radicals. Neurology 34:315-320

33. Patt A, Harken AH, Burton LM, Rodell TC, Piermattei D, Schorr WJ, Parker NB, Berger EM, Horesch KR, Terada LS, Linas SL, Cheronis JC, Repine JE 1988 Xanthine oxidase-derived hydrogen peroxide contributes to ischemia reperfusion-induced edema in gerbil brains. J Clin Invest 81:1556-1562

34. Betz AL 1985 Identification of hypoxanthine transport and xanthine oxidase activity in brain capillaries. J Neurochem 4:574-579

35. Armstead WM, Mirro R, Busija DW, Leffler CW 1988 Postischemic generation of superoxide anion by newborn pig brain. Am J Physiol 225:H401$\mathrm{H} 403$

36. Rosenberg AA, Murdaugh E, White CW 1989 The role of oxygen free radicals in post asphyxia cerebral hypoperfusion in newborn lambs. Pediatr Res 26:215-219

37. Palmer C, Vannucci RC, Towfighi J, du Plessis AJ, Vickers F 1990 Allopurinol reduces hypoxic-ischemic brain injury. Pediatr Res 27:332-336.

38. Myers RE, Yamaguchi S 1977 Nervous system effects of cardiac arrest in monkeys. Preservation of vision. Arch Neurol 34:65-74

39. Myers RE 1979 A unitary theory of causation of anoxic and hypoxic brain pathology. In: Fahn S, David J, Rowland L (eds) Cerebral Hypoxia and Its Consequences. Raven Press, New York, pp 195-213

40. Kalimo H, Rehncroná S, Soderfeldt B, Olsson Y, Siesjö BK 1981 Brain lactic acidosis and ischemic cell damage: II Histopathology. J Cereb blood Flow Metabol 1:313-327

41. Pulsinelli WA, Waldman S, Rawlinson D, Plum F 1982 Moderate hyperglycemia augments ischemic brain damage: A neuropathological study in the rat. Neurology 32:1239-1246

42. Pulsinelli WA, Levy DE, Sigsbee B, Scherer P, Plum F 1983 Increased damage after ischemic stroke in patients with hyperglycemia with or without diabetes mellitus. Am J Med 74:540-544

43. Rehncroná S, Rosén I, Siesjö BK 1980 Excessive cellular acidosis: an important mechanism of neuronal damage in the brain? Acta Physiol Scand 110:435-437

44. Rehncroná S, Rosén I, Siesjö BK 1981 Brain lactic acidosis and ischemic cell damage: 1. Biochemistry and Neurophysiology. J Cereb Blood Flow Metabol 1:297-311

45. Welsh FA, Ginsberg MD, Reider W, Buff WW 1980 Deleterious effect of glucose pretreatment on recovery from diffuse cerebral ischemia in the cat II. Regional metabolite levels. Stroke 11:355-363

46. Dawes GS, Hibbard E, Windle WF 1964 The effect of alkali and glucose infusion on permanent brain damage in rhesus monkeys asphyxiated at birth. J Pediatr 65:801-806

47. Adamsons K, Behrman R, Dawes GS, James LS, Coford C 1964 Resuscitation by positive pressure ventilation and tris-hydroxymethylaminomethane of rhesus monkeys asphyxiated at birth. J Pediatr 65:807-811

48. Britton SW, Kline RF 1945-46 Age, sex, carbohydrate, adrenal cortex and other factors in anoxia. Am J Physiol 145:190-202

49. Himwich HE, Bernstein AO, Herrlich H, Chesler A, Fazekas JF 1942 Mechanisms for the maintenance of life in the newborn during anoxia. Am J Physiol 35:387-391

50. Voorhies JM, Rawlinson D, Vannucci RC 1986 Glucose and perinatal hypoxic-ischemic brain damage in the rat. Neurology $36: 1115-1118$ 
51. Moore TJ, Lione AP, Regen DM, Tarpley HL, Raines PL 1971 Brain glucose metabolism in the newborn rat. Am J Physiol 221:1746-1753

52. Vannucci RC, Vasta F, Vannucci SJ 1987 Cerebral metabolic responses of hyperglycemic immature rats to hypoxia-ischemia. Pediatr Res 21:524-529

53. Vannucci RC, Christensen MA, Stein DT 1989 Regional cerebral glucose utilization in the immature rat: effect of hypoxia-ischemia. Pediatr Res 26:208-214

54. Gardiner M, Smith M, Kagstrom E 1982 Influence of blood glucose concentration on brain lactate accumulation during severe hypoxia and subsequent recovery of brain energy metabolism. J Cereb Blood Flow Metabol 2:429_ 438

55. Paschen W, Djuricic B, Mies G, Schmidt-Kastner R, Linn F 1987 Lactate and $\mathrm{pH}$ in the brain: association and dissociation in different pathophysiological states. J Neurochem 48:154-159

56. Welsh FA, O'Connor MJ, Langfitt TW 1977 Regions of cerebral ischemia located by pyridine nucleotide fluorescence. Science 198:951-953

57. Welsh FA 1984 Regional evaluation of ischemic metabolic alterations. J Cereb Blood Flow Metabol 4:309-316

58. Fonnum F 1984 Glutamate: a neurotransmitter in mammalian brain. J Neurochem 42:1-11

59. Rothman SM, Olney JW 1986 Glutamate and the pathophysiology of hypoxic-ischemic brain damage. Ann Neurol 19:105-111

60. Greenamyre JT, Olson JMM, Penney JB, Young AB 1985 Autoradiographic characterization of N-methyl-D-aspartate-, quisqualate- and kainate-sensitive glutamate binding sites. J Pharmacol Exp Ther 233:254-263

61. Greenamyer JT, Penney JB, Young AB, Hudson C, Silverstein F, Johnston MV 1987 Evidence for transient perinatal glutamatergic innervation of globus pallidus. J Neurosci 7:1022-1030

62. Siesjö BK, Bengtsson F 1989 Calcium fluxes, calcium antagonists and calcium-related pathology in brain ischemia, hypoglycemia, and spreading depression: A unifying hypothesis. J Cereb Blood Flow Metabol 9:127-140

63. Lucus DR, Newhouse JP 1957\% The toxic effect of sodium-L-glutamate on the inner layers of retina. AMA Arch Ophthalmol 58:193-201

64. Olney JW 1969 Brain lesions, obesity and other disturbances in mice treated with monosodium glutamate. Science 164:719-721

65. Kass IS, Lipton P 1982 Mechanisms involved in irreversible anoxic damage to the in vitro rat hippocampal slice. J Physiol 332:459-472

66. Rothman SM 1983 Synaptic activity mediates death of hypoxic neurons. Science 220:536-537

67. Rothman S 1984 Synaptic release of excitatory amino acid neurotransmitter mediates anoxic neuronal death. J Neurosci 4:1884-1891

68. Clark G, Samaie M, Rothman S 1985 Blockade of synaptic transmission protects rat hippocampal slice from hypoxia. Ann Neurol 18:385-386

69. Novelli A, Reilly JA, Lysko PG, Henneberry RC 1988 Glutamate becomes neurotoxic via the $\mathrm{N}$-methyl-D-aspartate receptor when intracellular energy levels are reduced. Brain Res 451:205-212

70. Coyle JT, Bird SJ, Evans RH, Gulley RL, Nadler JV, Nicklas WJ, Olney JW 1981 Excitatory amino acid neurotoxins: selectivity, specificity and mechanism of action. Neurosci Res Prog Bull 19:329-427

71. McBean GJ, Roberts PJ 1984 Chronic infusion of L-glutamate causes neurotoxicity in rat striatum. Brain Res 290:372-375

72. Steiner HX, McBean GJ, Kohler C, Roberts PJ, Schwarcz R 1984 Ibotenateinduced neuronal degeneration in immature rat brain. Brain Res 307:117124

73. Silverstein FS, Chen R, Johnston MV 1986 The glutamate analogue quisqualic acid is neurotoxic in striatum and hippocampus of immature rat brain. Neurosci Lett 71:13-18

74. McDonald JW, Silverstein FS, Johnston MV 1988 Neurotoxicity of N-methyl$\mathrm{D}$-aspartate is markedly enhanced in developing rat central nervous system. Brain Res 459:200-203

75. Pulsinelli WA 1985 De-afferentation of the hippocampus protects CAl pyramidal neurons against ischemic injury. Stroke $16: 144$

76. McDonald JW, Silverstein FS, Johnston MV 1987 MK-801 protects the neonatal brain from hypoxic-ischemic damage. Eur J Pharmacol 140:359361

77. Kochhar A, Zivin JA, Lyden PD, Mazzarella V 1988 Glutamate antagonist therapy reduces neurologic deficits produced by focal central nervous system ischemia. Arch Neurol 45:148-153

78. Park CK, Nehls DG, Graham DI, Teasdale GM, McCulloch J 1988 The glutamate antagonist MK-801 reduces focal ischemic brain damage in the rat. Ann Neurol 24:543-551

79. Hattori H, Marin AM, Schwartz PH, Fujikawa DG, Wasterlain CG 1989 Posthypoxic treatment with MK-801 reduces hypoxic-ischemic damage in the neonatal rat. Neurology 39:713-718

80. Mordecai Y-TG, Busto R, Dietrich WD, Martinez E, Valdes I, Ginsberg MD 1988 Effect of ischemia on the in vivo release of striatal dopamine, glutamate and $\gamma$-aminobutyric acid studied by intracerebral microdialysis. J Neurochem 51:1455-1464

81. Mordecai Y-TG, Busto R, Dietrich WD, Martinez E, Valdes I, Ginsberg MD 1988 Intra-ischemic extracellular release of dopamine and glutamate is associated with striatal vulnerability to ischemia. Neurosci Lett 91:36-40

82. Meldrum B 1985 Excitatory amino acids and anoxic-ichemic brain damage. Trends Neurosci 8:47-48

83. Kirino T 1982 Delayed neuronal death in the gerbil hippocampus following ischemia. Brain Res 239:57-69

84. Pulsinelli WA, Brierley JB, Plum F 1982 Temporal profile of neuronal damage in a model of transient forebrain ischemia. Ann Neurol 11:499-509

85. Worley PF, Baraban JM, Snyder SH 1987 Beyond receptors: multiple secondmessenger systems in brain. Ann Neurol 21:217-229

86. Nishizuka Y 1984 Turnover of inositol phospholipids and signal transduction. Science 225:1365-1370

87. Steiner AL, Ferrendelli JA, Kipnis DM 1972 Radioimmunoassay for cyclic nucleotides. J Biol Chem 247:1121-1124

88. Lust WD, Mrsulja BB, Mrsulja BJ, Passonneau JV, Klatzo I 1975 Putative neurotransmitters and cyclic nucleotides in prolonged ischemia of the cerebral cortex. Brain Res 98:394-399

89. Kobayashi M, Lust WD, Passonneau JV 1977 Concentrations of energy metabolites and cyclic nucleotides during and after bilateral ischemia in the gerbil cerebral cortex. J Neurochem 29:53-59

90. Huang SF-L, Sun GY 1986 Cerebral ischemia induced quantitative changes in rat brain membrane lipids involved in phosphoinositide metabolism. Neurochem Int 9:185-190

91. Ikeda M, Yoshida S, Busto R, Santiso M, Ginsberg MD 1986 Polyphosphoinositides as a probable source of brain free fatty acids accumulated at the onset of ischemia. J Neurochem 47:123-132

92. Chen C-K, Silverstein FS, Fisher SK, Statman D, Johnston MV 1988 Perinatal hypoxic-ischemic injury enhances quisqualic acid-stimulated phosphoinositide turnover. J Neurochem 51:353-359

93. Huang H-M, Gibson GE 1989 Phosphatidylinositol metabolism during in vitro hypoxia. J Neurochem 52:830-835

94. Greenberg DA 1987 Calcium channels and calcium channel antagonists. Ann Neurol 21:317-330

95. Simon RP, Griffiths T, Evans MC, Meldrum BS 1984 Calcium overload in selectively vulnerable neurons of the hippocampus during and after ischemia: an electron microscopy study in the rat. J Cereb Blood Flow Metabol 4:350361

96. Chen ST, Hsu CY, Hogan EL, Juan HY, Banik NK, Balentine JD 1987' Brain calcium content in ischemic infarction. Neurology 37:1227-1229

97. Deshpande JK, Siesjö BK, Wieloch T 1987 Calcium accumulation and neuronal damage in the rat hippocampus following cerebral ischemia. $\mathrm{J}$ Cereb Blood Flow Metabol 7:89-95

98. Van Reempts J, Borgers M 1985 Ischemic brain injury and cell calcium: morphologic and therapeutic aspects. Ann Emerg Med 14:736 742

99. Dienel GA 1984 Regional accumulation of calcium in postischemic rat brain. J Neurochem 43:913-925

100. Stein DT, Vannucci RC 1988 Calcium accumulation during the evolution of hypoxic-ischemic brain damage in the immature rat. $\mathrm{J}$ Cereb Blood Flow Metabol 8:834-842 